\title{
PROPERTIES OF FaL-G HOLLOW MASONRY BLOCKS
}

\author{
Niranjan PS ${ }^{1}$, Radhakrishna ${ }^{2}$ \\ ${ }^{1}$ Research Scholar, $R$ V College of Engineering Bangalore-560059 \\ ${ }^{2}$ Associate Professor and Dean-Civil Engineering
}

\begin{abstract}
FaL-G is the product name derived from a cementitious mixture composed of Fly ash (Fa), Lime (L) and Gypsum (G). It is a low-cost and environmental-friendly material. FaL-G in certain proportions, as a building material is an outcome of innovation. It gains strength like any other hydraulic cement in the presence of water. It is water resistant too. This paper addresses the technology of making FaL-G mortar compressed hollow blocks with low-calcium (Class F) dry fly ash as the base material. The FaL-G masonry hollow blocks were prepared without the use of conventional cement. Quarry dust and sand were used as fine aggregates as sustainable materials. The properties of FaL-G masonry hollow blocks were determined for different parameters. The experimental results reveal that the FaL-G hollow blocks are suitable to be used for the construction of masonry structures.
\end{abstract}

Keywords: fly ash, lime, gypsum, quarry dust, sand, mortar, hollow blocks.

\section{INTRODUCTION}

Every moment the emission of carbon dioxide into the atmosphere is being increased gradually. Considerable amount of fossil fuel, coal and oil are burnt to satisfy the human needs. This weakens the heat-trapping blanket that surrounds the planet and causes global warming. different alternatives can be considered to protect the planet. The rapid increase in the capacity and number of thermal power generation has resulted in the production of a huge quantity of fly ash. The prevailing disposal methods are not free from environmental pollution and other hurdles. On the other hand, the production of each ton of cement releases equal amount of carbon dioxide to the atmosphere. The usage of cement can be reduced by using the other possible alternative cementing materials without compromising the properties.

The most basic building material for construction of houses is the usual burnt clay brick in many countries. A significant quantity of fuel is utilized in making these bricks. Also, continuous removal of topsoil, in producing conventional bricks creates lot of environmental problems. There is strong need to adopt cost effective sustainable technology using local materials . Different methods are adopted to produce the building blocks using cement, lime-fly ash, lime-slag bindings and other materials. There is a need to develop simple and effective technologies for producing the masonry units. The need to produce more building materials for various elements of construction and the role of alternative options would be in sharp focus. The possibility of using innovative building materials and technologies, using waste material like fly ash, lime and gypsum has been considered in this paper.

FaL-G in certain proportions, as a building material, is an outcome of innovation to promote the utilization of fly ash by
Bhanumathidas and Kalidas [1]. It gains strength like any other hydraulic cement, in the presence of water, and is water resistant with time.

Large amounts of materials like gypsum and fly ash are available at phosphoric acid manufacturing plants and thermal power plants, respectively. These can be used to source sulphate and silica alumina. Gypsum contains impurities of phosphate, fluoride, organic matter and alkalies which prevent its direct use as building material. It is one of the calcium sulphate's rich residues. Phosphogypsum is an important byproduct of phosphoric acid fertilizer industries. It consists of $\mathrm{CaSO} 4.2 \mathrm{H} 2 \mathrm{O}$ and contains some impurities such as phosphate, fluoride, organic matter and alkalies. Approximately 5 million tons of phosphogypsum is being produced each year in India [2]. Cementitious binder, FaL-G, finds extensive application in the manufacturing of building materials such as bricks, ,solid blocks, hollow blocks and lean concrete. FaL-G technology enables production of hollow blocks with a simple process of mixing and water curing. Due to such appropriate technology, conservation of energy and pollution control are achieved [3].

It has been reported that FaL-G mortar can be used in making the masonry hollow block units by different combinations of fly ash, lime and phosphogypsum [4]. FaL-G technology contributes to the conservation of energy and reduces environmental degradation effectively [5]. Since it is manufactured using industrial wastes and marginal materails, the environmental impacts are mitigated. FaL-G units have the advantage of continuous year-wide operation and hence provide year-long employment opportunity to skilled artisans[6]. It creates self-help livelihood opportunities for the people in developing countries. In certain cases, where byproduct lime is not available, ordinary Portland cement is used 
as the source of lime, producing the same quality of bricks and blocks $[7,8]$.

\section{SCOPE OF RESEARCH}

FaL-G is relatively economical material derived from binders fly ash, lime and gypsum. The research reported till date speaks about the arbitrary use of the material without any rational approach. The report on proportioning, strength development in FaL-G is scarce. Also there is large scope for the development of FaL-G hollow blcoks made from mortar. In this research, FaL-G mortar hollow blocks were prepared and various properties were studied.

\section{MATERIALS AND METHODS}

Class F fly ash was procured from Raichur thermal power plant, Raichur,India. Commercially available lime was slaked and sieved through $1.18 \mathrm{~mm}$ sieve and stored in air tight container to maintain the freshness. Dry calcinated phosphogypsum was procured from a nearby fertilizer industry. The weighed quantity of class F fly ash and gypsum were mixed in dry condition. Lime was added to the mixture to obtain a uniform mix. This mixure was termed as FaL-G binder.

FaL-G mortar was prepared using FaL-G as binder and Quarry dust/sand/pond ash as fine aggregates. The procedure adopted was same as that of conventional cement mortar. Tap water was used to mix the ingredients. The ingredients were mixed thoroughly by kneading until the mass attained uniform consistency. FaL-G mortar was a dry frictional material at water/binder ratio of 0.2. FaL-G compressed hollow blocks were prepared using FaL-G mortar at various binder-fine aggregate ratios. The details of mix used for preparing FaL-G hollow blocks are indicated in Table 1. The FaL-G mixes were designated as $\mathrm{H} 1-\mathrm{H} 16$ for convenience.

Table1: Mix proportions of FaL-G bricks

\begin{tabular}{|c|c|c|c|c|c|}
\hline \multirow{2}{*}{$\begin{array}{c}\text { Mix } \\
\text { designation }\end{array}$} & \multicolumn{3}{|c|}{ FaL-G Binder proportion } & \multirow{2}{*}{ Fine aggregate } & \multirow{2}{*}{$\begin{array}{c}\text { FaL-G Binder: } \\
\text { Fine aggregate Ratio }\end{array}$} \\
\hline & Fly ash & Lime & Gypsum & & \\
\hline $\mathrm{H} 1$ & 50 & 40 & 10 & Stone dust & $1: 1$ \\
\hline $\mathrm{H} 2$ & 50 & 40 & 10 & Stone dust & $1: 1.5$ \\
\hline $\mathrm{H} 3$ & 55 & 35 & 10 & Stone dust & $1: 1$ \\
\hline $\mathrm{H} 4$ & 55 & 35 & 10 & Stone dust & $1: 1.5$ \\
\hline $\mathrm{H} 5$ & 60 & 30 & 10 & Stone dust & $1: 1$ \\
\hline H6 & 60 & 30 & 10 & Stone dust & $1: 1.5$ \\
\hline $\mathrm{H} 7$ & 65 & 25 & 10 & Stone dust & $1: 1$ \\
\hline H8 & 65 & 25 & 10 & Stone dust & $1: 1.5$ \\
\hline $\mathrm{H} 9$ & 50 & 40 & 10 & Sand & $1: 1$ \\
\hline $\mathrm{H} 10$ & 50 & 40 & 10 & Sand & $1: 1.5$ \\
\hline H11 & 55 & 35 & 10 & Sand & $1: 1$ \\
\hline H12 & 55 & 35 & 10 & Sand & $1: 1.5$ \\
\hline H13 & 60 & 30 & 10 & Sand & $1: 1$ \\
\hline H14 & 60 & 30 & 10 & Sand & $1: 1.5$ \\
\hline H15 & 65 & 25 & 10 & Sand & $1: 1$ \\
\hline H16 & 65 & 25 & 10 & Sand & $1: 1.5$ \\
\hline
\end{tabular}

Moulds of internal dimension $400 \mathrm{~mm}$ x150 mm x $200 \mathrm{~mm}$ were used for casting the compressed hollow blocks using FaL-G. The FaL-G mortar mix was placed in the moulds in two layers. Each layer was compacted and compressed using a vibrating table. The compressed brick was then de moulded and stored on the platform. They were cured in wet gunny bags for a day or two. Later they were cured by sprinkling water till the age of 28 days or date of testing whichever was earlier. The properties of FaL-G hollow blocks were studied like dry density, Initial rate of absorption, water absorption, Compressive strength of block and stress- strain characteristics.

\section{RESULTS AND DISCUSSION}

The properties of the FaL-G bricks are indicated in Table 2 for all the series H1-H16 considered. It was found that the density of FaL-G hollow blocks was in the range of 1.465 to $1.654 \mathrm{~g} / \mathrm{cc}$ for all the series. This density was marginally less compared to the conventional concrete hollow block available in the open market.

The initial rate of water absorption of the bricks varied from 3.92 to $4.4 \mathrm{~kg} / \mathrm{m} 2 / \mathrm{min}$ which is considered as less as per ASTM C-67 [9]. The percentage of water absorption was 
found to be less than $17.56 \%$ for all the series against the maximum limit of $20 \%$ as per IS $3495-1976[10]$.

Table2: Properties of hollow blocks of size 400mm x150mm x 200mm

\begin{tabular}{|c|c|c|c|}
\hline $\begin{array}{c}\text { Mix } \\
\text { designation }\end{array}$ & $\begin{array}{c}\text { Average Dry } \\
\text { density in g/cc }\end{array}$ & $\begin{array}{c}\text { Average Initial rate } \\
\text { of absorption of brick } \\
\text { in kg/m2/min }\end{array}$ & $\begin{array}{c}\text { Average water } \\
\text { absorption of brick } \\
\text { in \% }\end{array}$ \\
\hline H1 & 1.635 & 3.960 & 15.786 \\
\hline H2 & 1.654 & 3.928 & 15.712 \\
\hline H3 & 1.622 & 3.981 & 15.924 \\
\hline H4 & 1.637 & 3.944 & 15.804 \\
\hline H5 & 1.597 & 4.040 & 16.159 \\
\hline H6 & 1.619 & 3.986 & 16.052 \\
\hline H7 & 1.585 & 4.072 & 16.287 \\
\hline H8 & 1.612 & 4.003 & 16.147 \\
\hline H9 & 1.535 & 4.197 & 16.788 \\
\hline H10 & 1.568 & 4.113 & 16.617 \\
\hline H11 & 1.507 & 4.273 & 17.089 \\
\hline H12 & 1.534 & 4.202 & 16.919 \\
\hline H13 & 1.492 & 4.348 & 17.262 \\
\hline H14 & 1.507 & 4.274 & 17.094 \\
\hline H15 & 1.465 & 4.408 & 17.564 \\
\hline H16 & 1.481 & 4.346 & 17.410 \\
\hline
\end{tabular}

The following Parameters are varied to study various properties of FaL-G hollow blocks.

- Age: 7, 14, 28, 56, 72 and 90 days

- Binder-to-aggregate ratio: 1:1 and 1:1.5

- Quantity of fly ash : 50, 55, 60 and $65 \%$

- Quantity of lime : 25, 30,35 and 40\%

Figures 1 and 2 show the variation of compressive strength of the FaL-G hollow blocks with age for quarry dust, and sand respectively. It is quite obvious that the strength increases with age in all the cases. It is due to continues reaction between the FaL-G binder and water as discussed in the introduction. The compressive strength was around $4 \mathrm{MPa}$ at the age of 28days and around $5.5 \mathrm{MPa}$ at the age of 90 days. The minimum strength at the age of 28 days is more than $3 \mathrm{MPa}$ in most of the cases. This strength would be sufficient to use them as masonry units as per IS 3495-1976 [10].

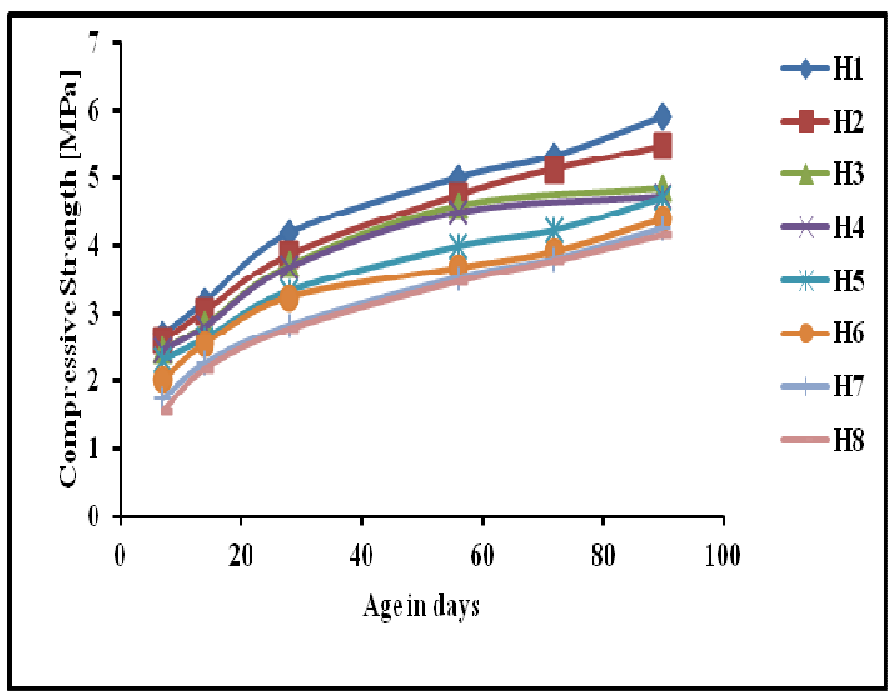

Fig. 1 Variation of Compressive Strength with age with Stone Dust as fine aggregate 


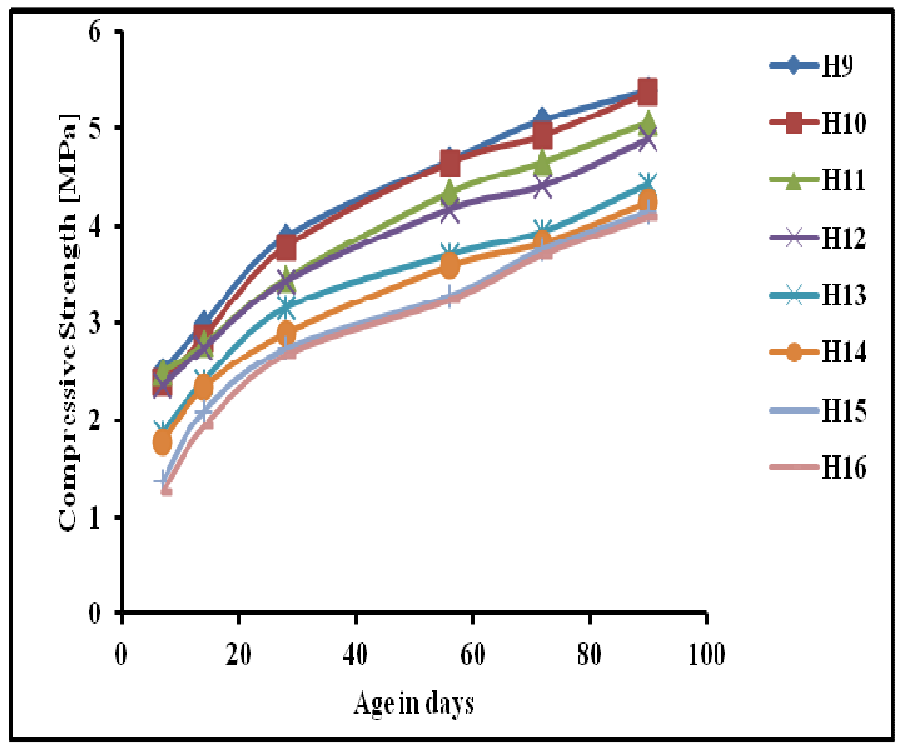

Fig. 2 Variation of Compressive Strength with age with Sand as fine aggregate

Figure 3 indicates the compressive strength of FaL-G bricks at the age of 7,14,28, 56, 72 and 90 days in order. The vertical bar in the graph indicates the strength of the brick having binder-to-aggregate ratio of $1: 1$ and $1: 1.5$ for different series H1to H8with quarry dust as fine aggregate. Similarly Figure 4 indicates for different series $\mathrm{H} 9$ to $\mathrm{H} 16$ with natural sand as fine aggregate. It can be observed that as the ratio of binderto-aggregate increases the strength decreases in all the cases. It is due to less binder availability in the mortar.

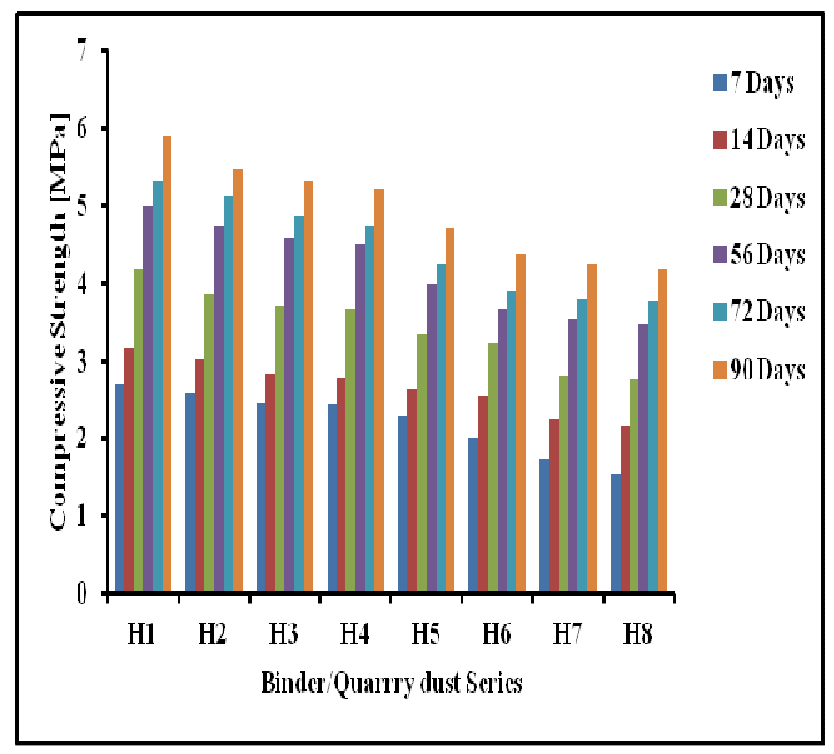

Fig. 3 Compressive Strength of H1 to H8 of Binder/Quarry dust Series for various ages

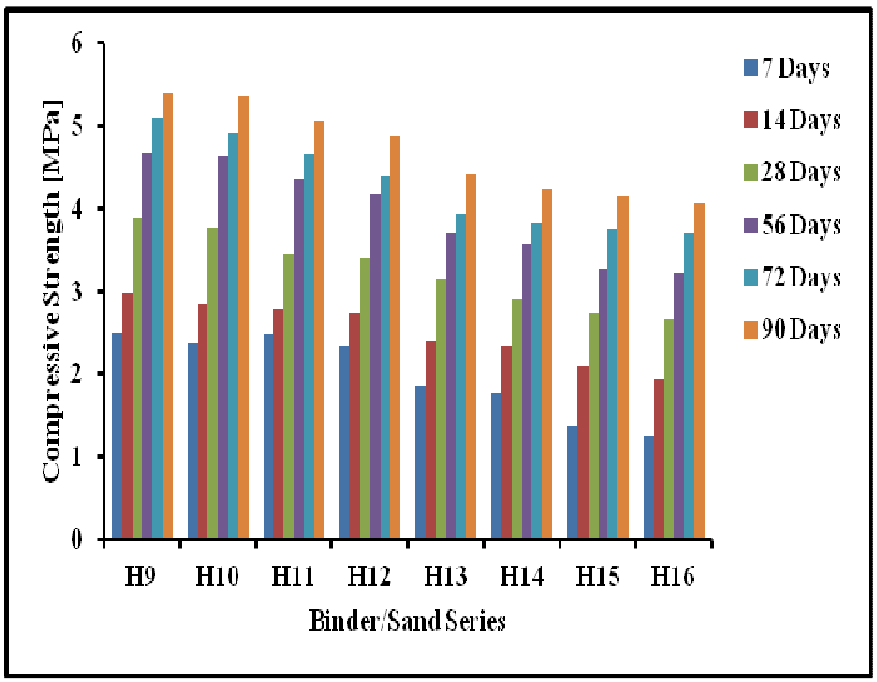

Fig. 4 Compressive Strength of H9 to H16 of Binder/Sand Series for various ages

The series considered for the variation of fly ash were $\mathrm{H} 1$ to H8 [binder/quarry dust series] and H9 to H16 [binder/Sand series] with $50,55,60$ and $65 \%$ of fly ash respectively. For convenience, the age of the blocks was considered upto 90 days with quarry dust and sand as fine aggregates. Figure 5 indicates the variation of compressive strength with the percentage of fly ash beyond $50 \%$. It was found that the compressive strength decreases with the increase in fly ash content, the optimum being 50\%. Same observation was found in the research reported by Radhakrishna [4].

The series considered for the variation of lime were $\mathrm{H} 1$ to $\mathrm{H} 16$ series with 4035,30 and $25 \%$ of lime respectively. The variation of compressive strength with the lime content is shown in Figure 6. It can be noticed that the increase in lime content increases the strength. In FaL-G, as the fly ash content increases the lime content should decrease as the gypsum is maintained at $10 \%$.

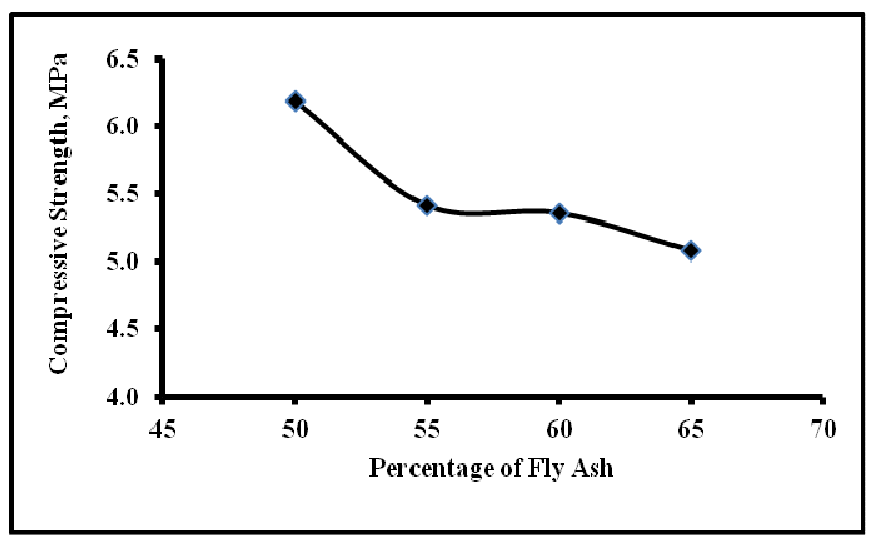

Fig. 5 Variation of Compressive Strength with fly ash content 


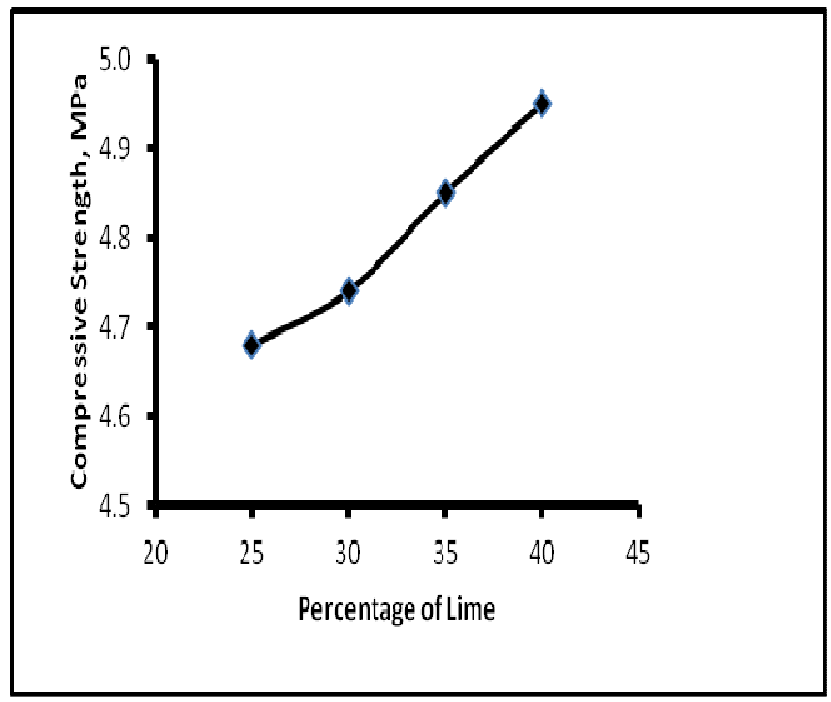

Fig. 6 Variation of Compressive Strength with lime content

Modulus of elasticity of hollow block were tested at 28 days for the series H1 [50:40:10], H3 [55:35:10] with quarry dust as fine aggregate, H9 [50:40:10], H11[55:35:10] with natural sand as fine aggregate. The modulus of elasticity was found to be $1768,1666,1876$ and $1527 \mathrm{MPa}$ at the age of 28 days respectively. Figures 7,8 9 and 10 indicate the stress-strain behaviour for different series of the hollow FaL-G blocks. This range of modulus of elasticity is quite satisfactory to use these bricks as masonry units.

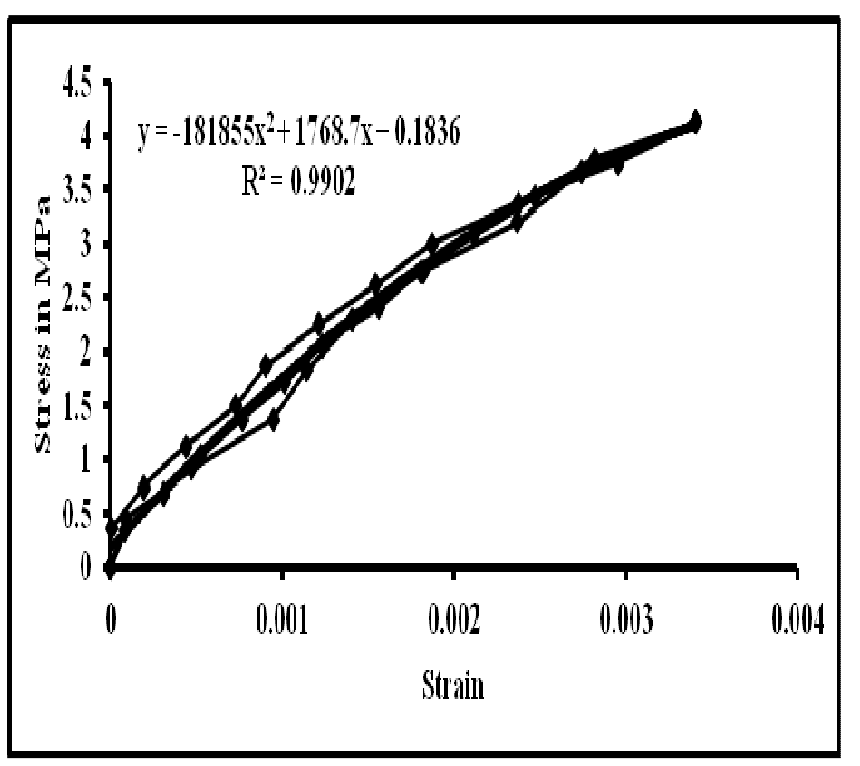

Fig. 7 Modulus of elasticity at 28 days of series H1[50:40:10][QD]

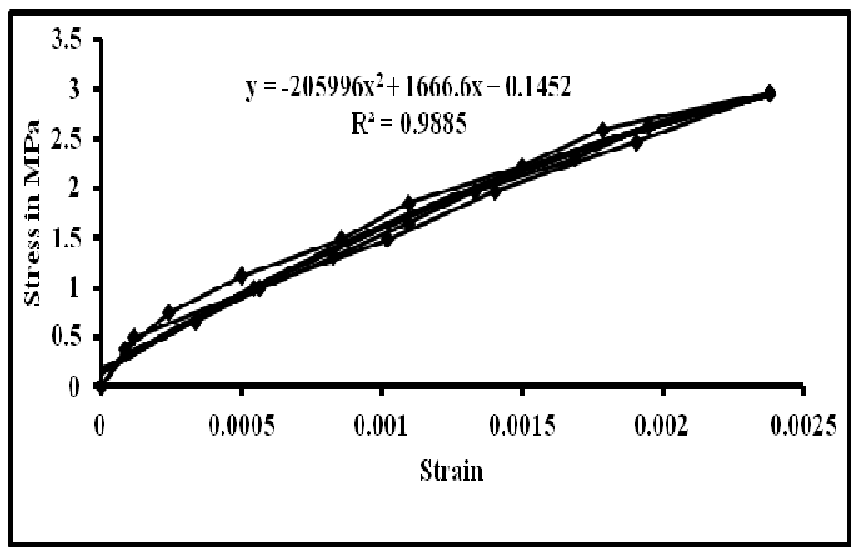

Fig. 8 Modulus of elasticity at 28 days of series $\mathrm{H} 3[55: 35: 10][\mathrm{QD}]$

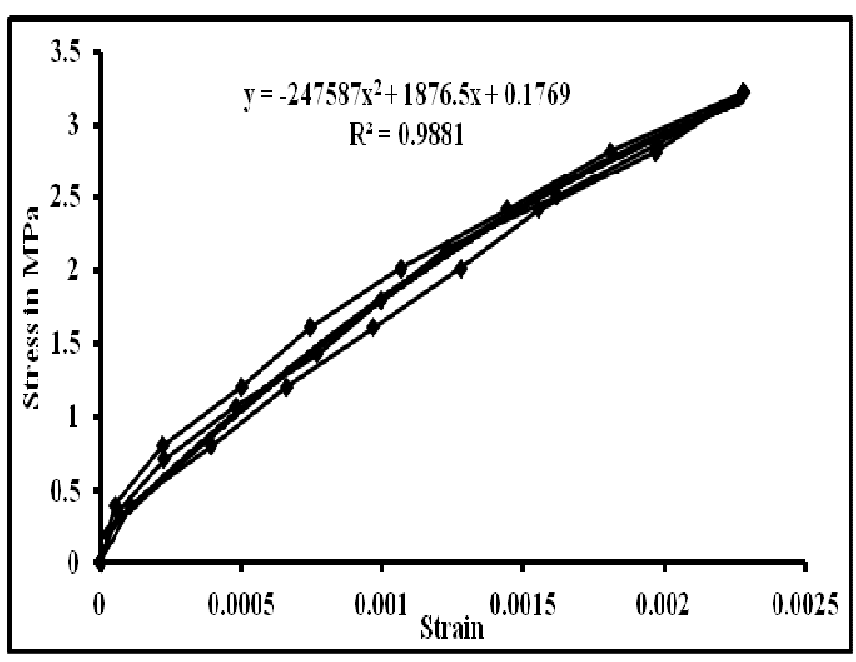

Fig. 9 Modulus of elasticity at 28 days of series H9[50:40:10][Sand]

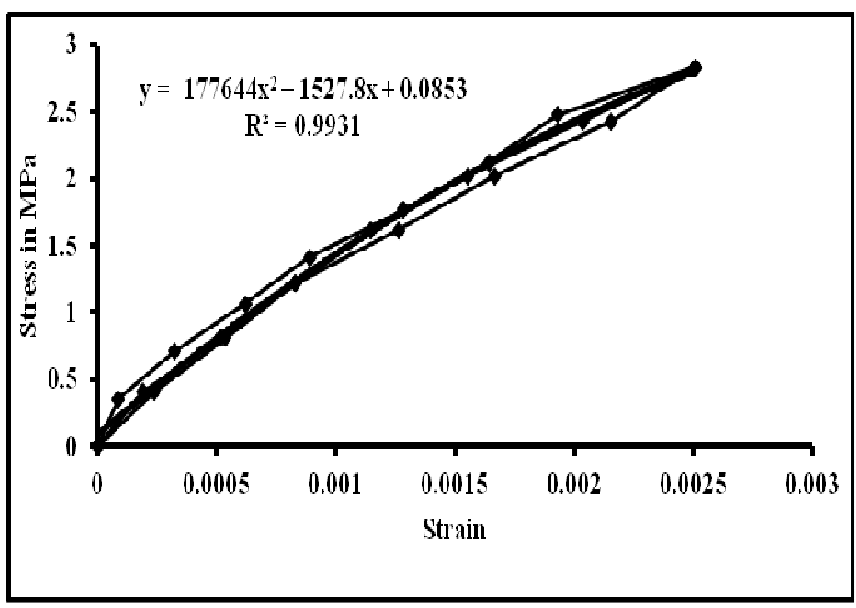

Fig. 7 Modulus of elasticity at 28 days of series H11 [55:35:10][Sand] 


\section{CONCLUDING REMARKS}

$>$ FaL-G compressed masonry hollow blocks can be conventionally prepared economically by using industrial wastes like fly ash, lime, gypsum, stone dust and Sand.

$>$ It was found that the dry density, IRA and water absorption of FaL-G compressed bricks were in the range of 1.465 to $1.654 \mathrm{~g} / \mathrm{cc}$., 3.92 to $4.4 \mathrm{~kg} / \mathrm{m}^{2} / \mathrm{min}$ and less than $17.56 \%$ respectively.

$>$ FaL-G hollow blocks attained considerable strength around $4 \mathrm{MPa}$ at the age of 28 days to use them as masonry units with adequate modulus of elasticity.

$>$ In view of the above, it can be concluded that FaL-G masonry units can effectively replace conventional masonry units.

\section{REFERENCES}

[1] Bhanumathidas, N and Kalidas, N. (2002) "FaL-G: Hydraulic cement", Proc. Of National workshop on Alternative Building Methods. Department of Civil Engg. Indian Institute of Science. Bangalore: 2002, pp.17-23.

[2] Singh.M. and M. Garg, (1997)," Durability of cementitious binder derived from industrial wastes", Mater Struct 30, pp. 607-612.

[3] Sunil Kumar., (2002),'A perspective study on fly ash-lime-gypsum bricks and hollow blocks for low cost housing development", Construction and Building Materials, Volume 16, Issue 8 , December 2002, 519-525.

[4] Radhakrishna, "Analysis and Assessment of Compressive Strength in FaL-G Composites”, The Journal of Solid Waste Technology and Management, Volume 36, No.2, May 2010, pp 110-127.

[5] Siamak Boudaghpour and AlirezaJadidi "Department of Environmental Engineering, K. N. Toosi, University of Technology, Iran. Islamic Azad University, Tehran Joyous, Iran "Accepted 09 July, 2009.

[6] N Bhanumathidas and N Kalidas "Second International Symposium on Concrete Technology for Sustainable Development" (27 Feb-3 Mar, 2005; Hyderabad).

[7] Bhanumathidas $\mathrm{N}$ and KalidasN: Dual Role of Gypsum: Set Retarder and Strength Accelerator; Indian Concrete Journal, March 2004.

[8] Bhanumathidas N and Kalidas N: Portland FaL-G: A New Pozzolanic Blend; Civil Engineering \& Construction Review; May 1994.

[9] ASTM C 67 - 12 'Standard Test Methods for Sampling and Testing Brick and Structural Clay Tile".

[10] IS 3495 (Parts 1 to 4): 1992, "Methods of Tests of Burnt Clay Building Bricks", Bureau of Indian Standards, India. 